\title{
Simultaneous targeting of 5-LOX-COX and EGFR blocks progression of pancreatic ductal adenocarcinoma
}

\author{
Chinthalapally V. Rao ${ }^{1}$, Naveena B. Janakiram ${ }^{1}$, Venkateshwar Madka ${ }^{1}$, Vishal \\ Devarkonda $^{1}$, Misty Brewer ${ }^{1}$, Laura Biddick ${ }^{1}$, Stan Lightfoot ${ }^{1}$, Vernon E. Steele ${ }^{2}$, \\ Altaf Mohammed ${ }^{1}$ \\ ${ }^{1}$ Center for Cancer Prevention and Drug Development, Department of Medicine, Hem-Onc Section, Stephenson Cancer \\ Center, University of Oklahoma Health Sciences Center, Oklahoma City, OK, USA \\ ${ }^{2}$ Division of Cancer Prevention, Chemopreventive Agent Development Research Group, National Cancer Institute, Bethesda, \\ MD, USA
}

Correspondence to:

Chinthalapally V. Rao, e-mail: cv-rao@ouhsc.edu

Altaf Mohammed, e-mail: altaf-mohammed@ouhsc.edu

Keywords: chemoprevention, inflammation, EGFR, pancreatic cancer

Received: July 31, $2015 \quad$ Accepted: September 16, $2015 \quad$ Published: September 28, 2015

\section{ABSTRACT}

Cyclooxygenase-2 (COX-2), 5-Lipoxygenase (5-LOX), and epidermal growth factor receptor (EGRF) are over-expressed in human pancreatic ductal adenocarcinoma (PDAC). Using next-generation sequencing (NGS) analysis, we show significant increase in COX-2, 5-LOX, and EGFR expression during PDAC progression. Targeting complementary pathways will achieve better treatment efficacy than a single agent high-dose strategy that could increase risk of side effects and tumor resistance. To target COX-2, 5-LOX, and EGFR simultaneously, we tested effects of licofelone (dual 5-LOX-COX inhibitor), and gefitinib (EGFR inhibitor), individually and in combination, on pancreatic intraepithelial neoplasms (PanINs) and their progression to PDAC using genetically engineered mice. Individually, licofelone (L) and gefitinib (G) significantly inhibited incidence of PDAC in male $(72 \% L, 90 \%, F, p<0001)$ and female $(90 \% \mathrm{~L}, \mathbf{8 5} \% \mathrm{G}, p<0.0001)$ mice. The combination drug treatment produced complete inhibition of PDAC in both genders. Pancreata of mice receiving combination treatment showed significantly fewer Dclk1-positive cancer stem-like cells, inhibition of COX-2, 5-LOX, PCNA, EGFR and $\beta$-catenin expression $(p<0.05-0.0002)$, increased p21 expression. Significant changes in tumor immune responses and desmoplastic reaction was observed by NGS analysis in combination treatment $(p<0.05)$. In summary, early simultaneous targeting of 5-LOX-COX- and EGFR pathways may provide additive inhibitory effects leading to complete suppression of PDAC.

\section{INTRODUCTION}

Pancreatic cancer is usually diagnosed at late stages, with almost uniform lethality. The five-year survival rate for this deadly cancer is $<7 \%$ [1]. Although gemcitabine is the drug of choice, survival following treatment is marginally improved, by only a few weeks. Hence, new chemopreventive and therapeutic treatment strategies are urgently needed. Research toward understanding this disease led to the identification of major risk factors and important molecular changes underlying pancreatic cancer initiation and progression.
The initiation of pancreatic cancer lesions and their progression to pancreatic ductal adenocarcinoma (PDAC) and further metastatic invasion are associated with inflammation. Several lines of evidence show that cyclooxygenase-2 (COX-2) and 5-lipoxygenase (5-LOX) are significantly over-expressed in cancers [2-5]. COX-2 and 5-LOX metabolites play a pivotal role in cell signaling and proliferation [2-5]. Their release has been demonstrated in response to epidermal growth factor (EGF) and growth stimuli. Preclinical studies show that COX-2 inhibitors may inhibit pancreatic cancer in vitro and in vivo; however, those studies have 
not been translated for clinical use [2-4]. Moreover, use of celecoxib, a COX-2 inhibitor, in the prevention of adenomatous polyps was associated with a significant increase in risk of cardiovascular (CV) events [6, 7]. In another study, the relative risk of $\mathrm{CV}$ events was 1.30 with the use of celecoxib, compared with placebo [8]. It is widely accepted that selectively blocking COX-2 will shift arachidonic acid metabolism towards the 5-LOX pathway, overproducing leukotrienes and leading to increased prothrombotic effects $[2,9]$. Thus, preclinical and clinical data underscore the importance of arachidonic acid metabolism-related inflammatory responses in pancreatic tumorigenesis.

Both COX-2 and EGFR are known to synergistically activate oncogenic signaling. COX-2 and epidermal growth factor receptor (EGFR) were found to be significantly expressed in pancreatic tumors. The expression of COX-2 and EGFR in the majority of undifferentiated pancreatic carcinomas suggests that COX-2 and EGFR might represent targets for adjuvant therapy in anaplastic pancreatic cancer [10]. The activation of the EGFR pathway promotes transcription of the COX-2 gene. Also, EGFR transcription and phosphorylation are activated by the COX-2 pathway. Since both these pathways are involved in inflammation and EGFR signaling that will lead to tumor cell growth, use of agents that combined inhibit both pathways simultaneously may provide synergy for improved tumor inhibition. Although EGFR inhibitors are in use, their benefits are limited and the use of higher doses leads to undesirable side effects and toxicities. Clinically, targeting inflammation by selective COX-2 inhibitors leads to increased cardiovascular and GI toxicities. Therefore, targeting both EGFR and 5-LOX-COX- simultaneously may be an effective approach to modulate three pathways and their downstream signaling, which may result in an increased treatment response. In the present study, we evaluated the potential anti-tumor effects of licofelone, a novel dual 5-LOX-COX- inhibitor (Fig. 1A), and gefitinib, a known EGFR inhibitor (Fig. 1B), either individually or in combination, by simultaneously modulating multiple targets (COX, 5-LOX, EGFR) using a genetically engineered Kras mouse model (GEM) of pancreatic cancer. This model has histopathology and molecular features similar to human pancreatic cancers [11]. The use of this mouse model has played a key role in the elucidation of the mechanisms and underlying pancreatic tumorigenesis, and in the identification of anti-tumor agents for the prevention of pancreatic cancer [12-18].

\section{RESULTS}

\section{General observations}

All GEM and wild-type mice were fed modified AIN-76A diets, with or without licofelone, gefitinib, or a combination (Fig. 1C). There were no significant differences in the bodyweights of control and licofelone-treated animals (Fig. 1D, 1E). However, a non-significant decrease was observed in the bodyweights of animals treated with gefitinib and the combination (Fig. 1D, 1E). Examination of the gross anatomy of GEM and wild-type mice revealed no visible evidence of any abnormality of the kidneys, liver, spleen, intestines, heart, or lungs. There were no significant differences in the weights of these organs in control and experimental-diet-fed mice, indicating that the agents did not produce any overt toxicity. However, pancreata from control-diet-fed GEM developed visible tumors and weighed significantly more than those from the control-diet-fed wild-type mice, which were completely free from tumor growth. Histopathological analysis of formalin-fixed tumors confirmed the presence of PanIN lesions and ductal adenocarcinoma in the pancreata of GEM. Thus, we observed organ-specific tumor growth due to specific p48 ${ }^{\mathrm{Cre} /+}$ activation of $\mathrm{Kras}^{\mathrm{G} 12 \mathrm{D} /+}$ in pancreata of GEM, which could be monitored for the potential effects of the test agents administered in diet.

\section{Inhibition of pancreatic tumor weight and PDAC incidence}

Pancreatic weight is a simple marker to assess tumor progression $[17,18]$. A significant increase in pancreas weight was observed in $\mathrm{p} 48^{\mathrm{Cre} /+}-\mathrm{LSL}-\mathrm{Kras}^{\mathrm{G} 12 \mathrm{D} /+}$ mice compared with wild-type mice (Fig. 2A). As summarized in Figs. 2A and 2B, the combination treatment caused a significant decrease in the weight of pancreatic tumors in $\mathrm{p} 48^{\mathrm{Cre} /+}-\mathrm{LSL}-\mathrm{Kras}^{\mathrm{G} 12 \mathrm{D} /+}$ mice. The pancreatic tumor weights in untreated control male and female GEM were $($ Mean $\pm S E M) 1.33 \pm 0.13$ and $1.005 \pm 0.16 \mathrm{~g}$, respectively. In GEM fed licofelone (L), gefitinib (G), or $\mathrm{L}+\mathrm{G}$, the pancreas weights were Mean \pm SEM 0.40 $\pm 0.03,0.43 \pm 0.27$, and $0.27 \pm 0.03 \mathrm{~g}$, respectively, in males, and $0.31 \pm 0.08 \mathrm{~g}, 0.38 \pm 0.02 \mathrm{~g}$, and $0.27 \pm 0.18 \mathrm{~g}$, respectively, in females. The pancreata of wild-type mice treated with $\mathrm{L}+\mathrm{G}$ weighed $0.26 \pm 0.02 \mathrm{~g}$ in male mice and $0.26 \pm 0.01 \mathrm{~g}$ in female mice. The pancreatic tumor weights were reduced by $80 \%(p<0.0001)$ with $\mathrm{L}+\mathrm{G}$ treatment in male mice and by $72 \%(p<0.001)$ in female mice (Fig. 2A, 2B). Extensive histopathologic analysis of the pancreas using H\&E-stained slides revealed no microscopic pathologic alterations in wild-type mice fed either AIN-76A or L+G-supplemented diets. In contrast, AIN76A-diet-fed male and female p48 ${ }^{\mathrm{Cre} /+}$ LSL$\mathrm{Kras}^{\mathrm{G} 12 \mathrm{D} /+}$ mice demonstrated $82 \%$ and $64 \%$ incidence of PDAC, respectively (Fig. 2C and 2D). L, G, and L+G treatments decreased PDAC incidence to $23 \%, 10 \%$, and $0 \%$, respectively, in male GEM, and to $6 \%, 10 \%$, and $0 \%$, respectively, in female GEM (Fig. 2C and 2D). The combination treatment of $\mathrm{L}+\mathrm{G}$ completely inhibited carcinoma incidence in both male and female GEM. 

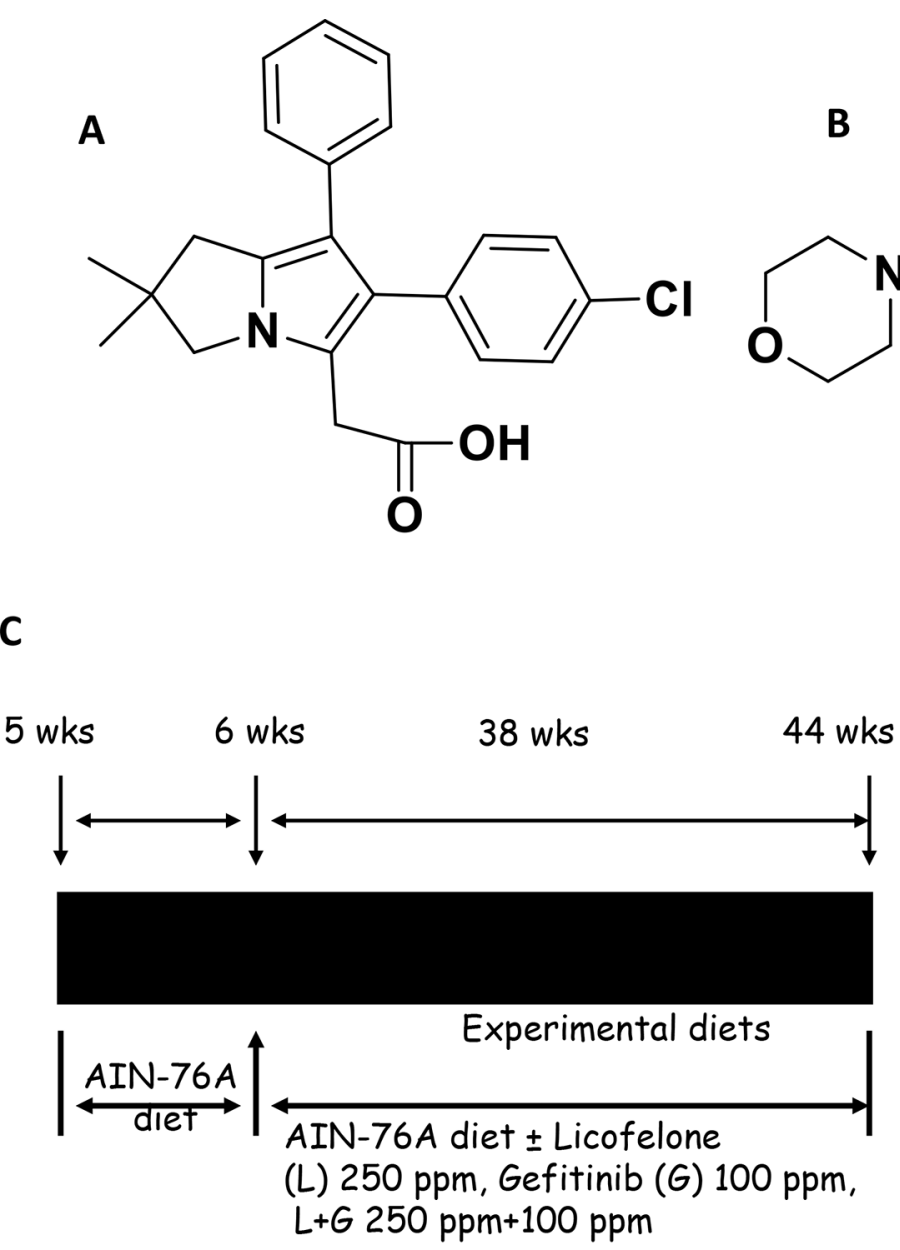<smiles>[B]Oc1cc2ncnc(Nc3ccc(F)c(Cl)c3)c2cc1OCCCN1CCOCC1</smiles>
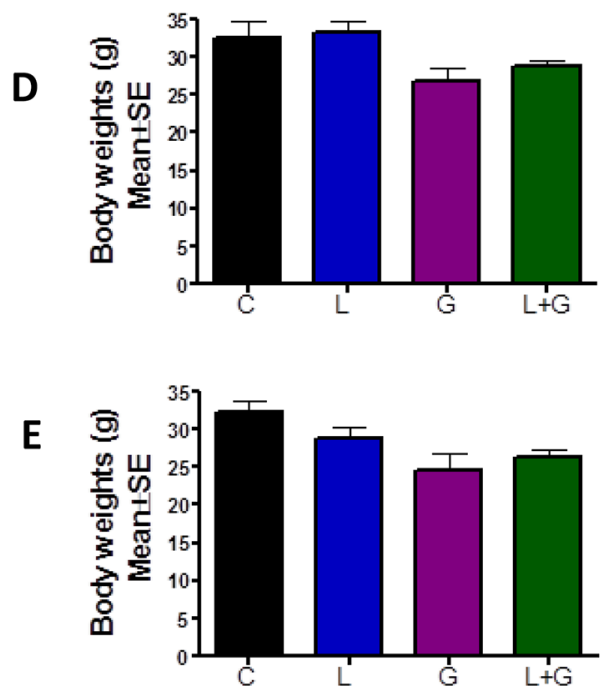

Figure 1: Experimental design for evaluation of licofelone and gefitinib efficacy in PC prevention in GEM. A-B. Structure of licofelone (A) and gefitinib (B) C. Experimental design for evaluation of licofelone, gefitinib, and a combination of licofelone $(\mathrm{L})+$ gefitinib $(\mathrm{G})$ efficacy in PC inhibition in male and female $\mathrm{p}^{\mathrm{C}} 8^{\mathrm{Cre} /+}$-LSL-Kras ${ }^{\mathrm{G} 12 \mathrm{D} /+}$ GEM mice. At six weeks of age, groups of mice (24-34/group for activated $\mathrm{p}^{\mathrm{Cre} /+}{ }^{\mathrm{C}}$-LSL-Kras ${ }^{\mathrm{G} 12 \mathrm{D} /+}$ or 12 /group for wild-type) were continuously fed AIN-76A diets containing $0,250 \mathrm{ppm}$ licofelone, or $100 \mathrm{ppm}$ gefitinib, alone or in combination, for 38 weeks. Each pancreas was evaluated histopathologically for marker expression as described in the text. D-E. Effect of licofelone, gefitinib, or the combination on bodyweight (BW; means $\pm S E)$ at termination of the experiment in male D. and female E. mice. No statistically significant differences were observed between control and drug-treated $\mathrm{p} 48^{\mathrm{Cre} /+}$-LSL-Kras ${ }^{\mathrm{G} 12 \mathrm{D} /+}$ or wild-type mice.

Fig. 2E-2H shows the H\&E staining of the pancreatic tumors with and without licofelone, gefitinib, and the combination treatment.

\section{Combination of licofelone and gefitinib inhibits PanIN lesion progression and carcinoma}

The total numbers of PanIN lesions in GEM fed AIN-76A diet were (means \pm SE) $502 \pm 22$ in male GEM and $604 \pm 29$ in female GEM. In the treatment groups, total PanINs in male mice were $398 \pm 19$ (licofelone), $410 \pm 38$ (gefitinib), and $340 \pm 25$ (combination), while total PanINs in female mice were $539 \pm 16$ (licofelone), $658 \pm 42$ (gefitinib), and $456 \pm 25$ (combination; Fig. 3A, 3B). In male GEM fed AIN-76A diet, PanINs by lesion classification were (means $\pm S E$ ): $188 \pm 30$
(PanIN 1), $160 \pm 16$ (PanIN 2), and $154 \pm 16$ (PanIN 3). In licofelone-treated male mice, PanIN numbers were $184 \pm 32$ (PanIN 1), $112 \pm 14$ (PanIN 2), and $102 \pm 13$ (PanIN 3). In male mice treated with gefitinib, PanIN numbers were $310 \pm 94$ (PanIN 1), $67 \pm 12$ (PanIN 2), and $32 \pm 8$ (PanIN 3). Finally, male mice receiving the combination treatment had the following PanINs: $223 \pm$ 43 (PanIN 1), $71 \pm 15$ (PanIN 2), and $46 \pm 17$ (PanIN 3; Fig. 3C).

The number of PanIN lesions in female GEM fed AIN-76A diet were (means \pm SE): $185 \pm 24($ PanIN 1), $181 \pm 14$ (PanIN 2), and $238 \pm 20$ (PanIN 3). In licofelone-treated female mice, PanIN numbers were $275 \pm 23($ PanIN 1), $161 \pm 10($ PanIN 2), and $103 \pm 15$ (PanIN 3). In female mice treated with gefitinib, Pan IN numbers were $368 \pm 79$ (PanIN 1), $170 \pm 26$ (PanIN 2), 

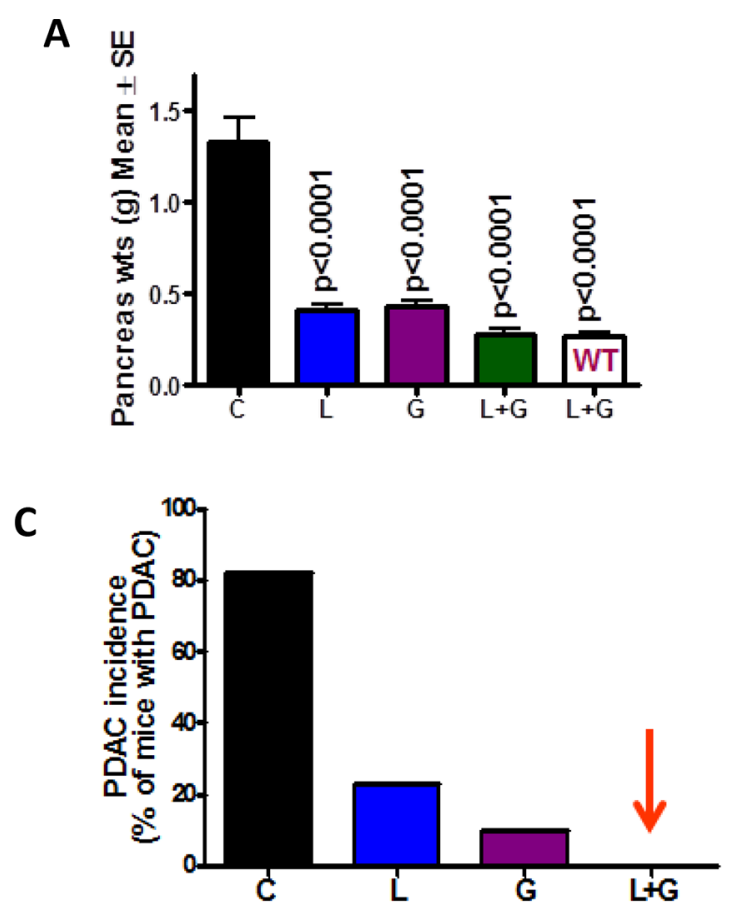

B
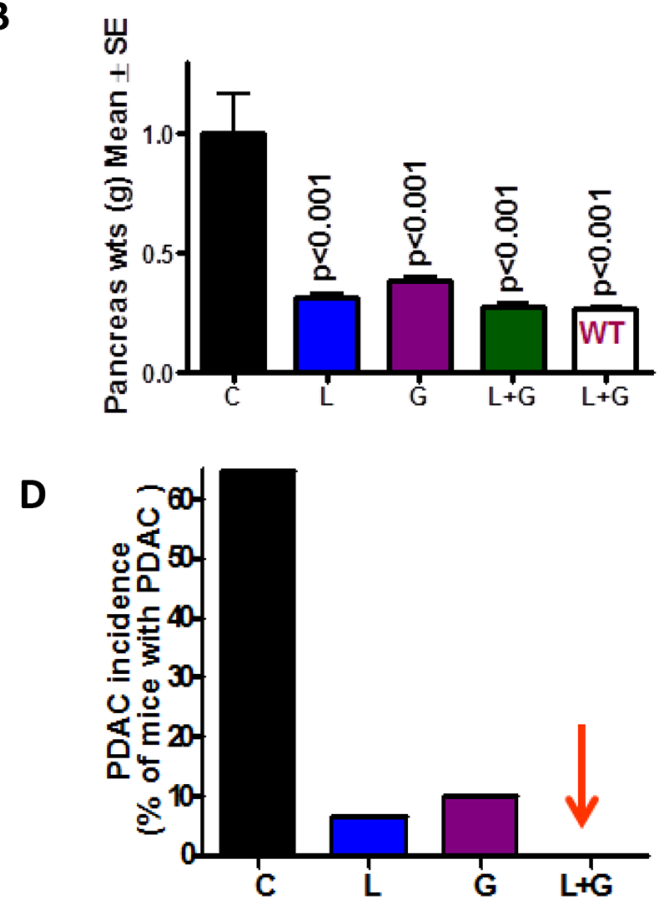
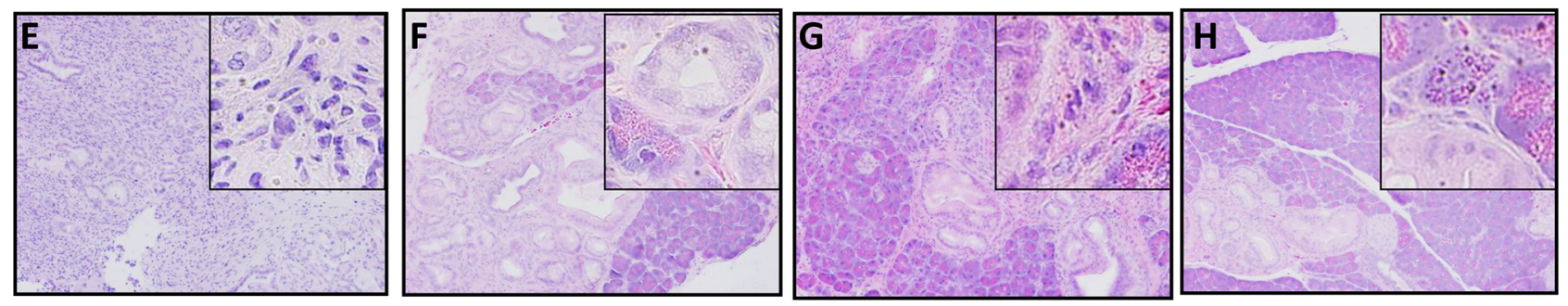

Figure 2: Effect of $\mathbf{L}, \mathbf{G}$ and $\mathbf{L}+\mathbf{G}$ on pancreatic tumor weights and PDAC incidence. Effect of $\mathrm{L}, \mathrm{G}$, and $\mathrm{L}+\mathrm{G}$ on pancreas weight at the termination of the experiment in male A. and female B. mice. $\mathrm{L}+\mathrm{G}$ significantly reduced pancreatic tumor weights. C-D. Effect of $\mathrm{L}, \mathrm{G}$, and $\mathrm{L}+\mathrm{G}$ on the incidence of PDAC in male C. and female D. mice. $\mathrm{L}+\mathrm{G}$ showed complete inhibition of PDAC. E-H. Histopathologic analysis of untreated and treated pancreata using Hematoxylin \& Eosin staining. Pancreata from untreated animals showing poorly differentiated adenocarcinoma with some of the cells invading stroma E. Pancreata from animals treated with L F. G G. and L+G H. showing PanIN lesions.

and $120 \pm 14$ (PanIN 3). Finally, female mice receiving the combination treatment had the following PanIN results: $260 \pm 37$ (PanIN 1), $122 \pm 17$ (PanIN 2), and $74 \pm 21$ (PanIN 3; Fig. 3D).

The number of PanIN 2 and PanIN 3 lesions or carcinoma in situ was suppressed by $\sim 70 \%$ in the combination-treated groups (Fig. 3C, 3D). A slight increase in the number of PanIN 1 lesions was observed in pancreata of mice treated with the combination, suggesting a potential blockade of further progression of these lesions to carcinoma in situ and PDAC. Carcinoma within the pancreas was completely inhibited in male and female GEM (Fig. 4A, 4B) receiving the combination treatment. Up to $70 \%$ of the pancreata from mice treated with the combination of licofelone and gefitinib appeared normal, i.e., free from PanIN lesions and carcinoma, whereas up to $4-5 \%$ of pancreata appeared normal in untreated GEM (Fig. 4C, 4D).

\section{Combination of licofelone and gefitinib inhibits tumor cell proliferation, induces apoptosis, and modulates inflammatory and EGFR signaling}

IHC/IHF, western immunoblotting, real-time PCR, and terminal deoxynucleotidyl transferase dUTP nick end labeling (TUNEL) assay approaches were used to determine the effects of the drug combination on tumor cell proliferation, apoptosis, and modulation of inflammatory and EGFR signaling in the pancreatic tissues of GEM (Fig. 5-8, Supplementary Fig. 1). IHC staining showed that PanIN lesions/carcinoma were labeled positively for

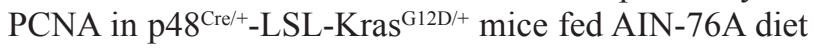
alone (Fig. 5A). Markedly decreased numbers of PCNApositive cells and proliferative index were observed in mice fed a licofelone+gefitinib combination-supplemented diet compared with individual drug-treated and controldiet-fed mice (Fig. 5A, 5B). Figs. 5C and 5D summarize 


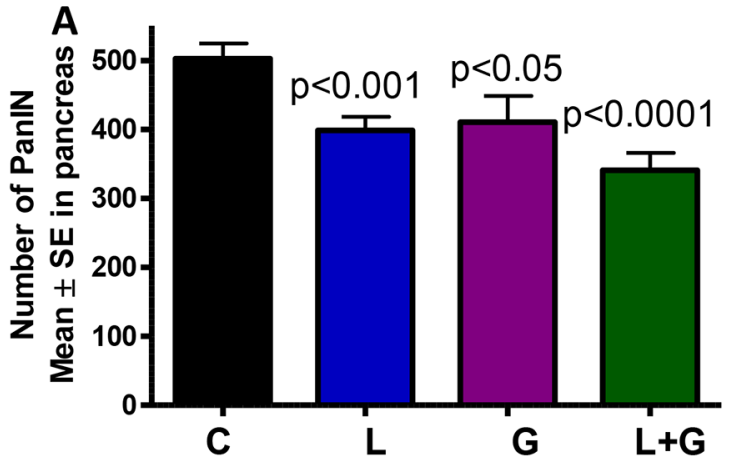

C

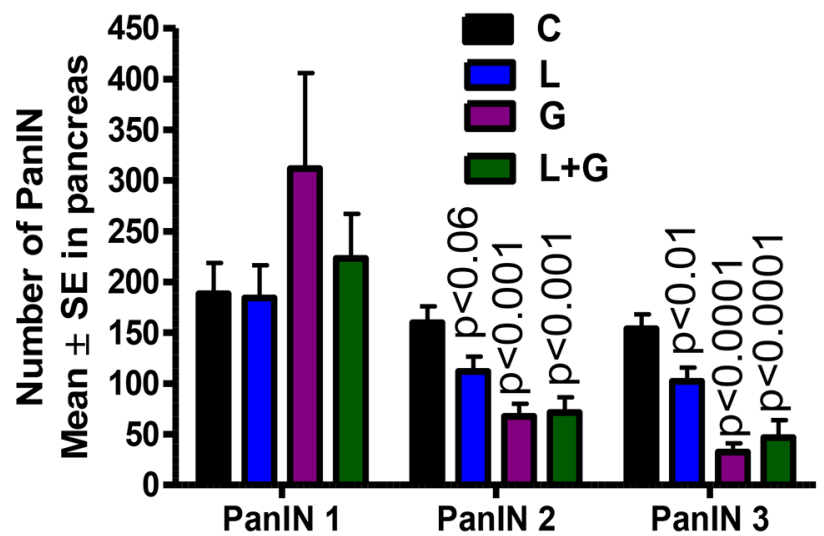

B

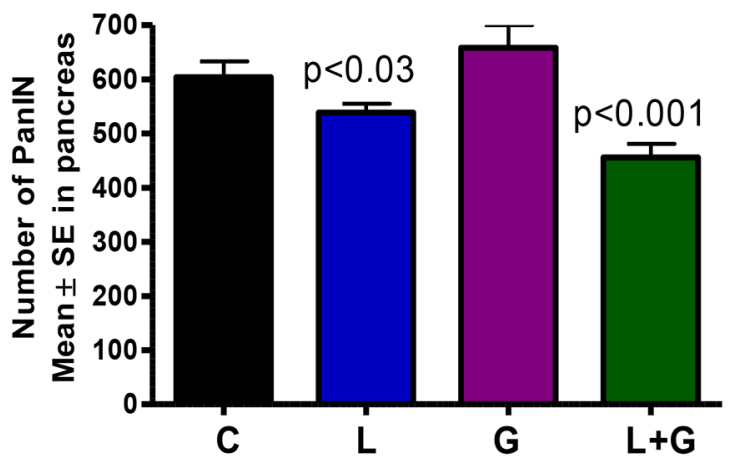

D

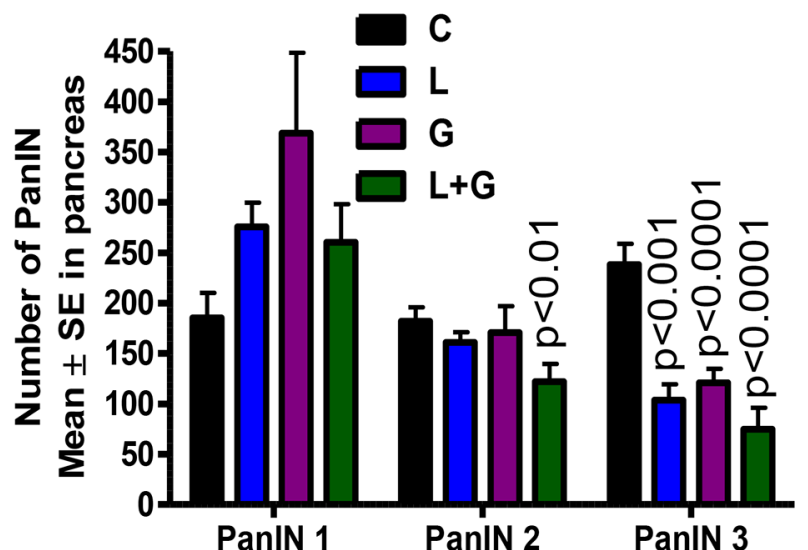

Figure 3: A-D. Effect of $\mathrm{L}, \mathrm{G}$, and $\mathrm{L}+\mathrm{G}$ on PanIN multiplicity in male $(\mathrm{A}, \mathrm{C})$ and female (B,D) GEM mice (means $\pm S E$ ).

the effects of licofelone, gefitinib, and the combination on tumor cell apoptosis.

Qualitative microscopic examination showed a substantial increase in TUNEL-positive cells in the pancreatic tumor tissue of mice treated with the combination. Quantification of TUNEL-positive cells from pancreata of control diet-fed mice showed $18 \pm 1.8$ (mean \pm SEM) compared with $62 \pm 1.4$ TUNEL-positive cells in pancreatic tumor tissue from combination-treated mice, accounting for a fivefold increase in the apoptotic index $(p<0.0001$, Fig. 5D). Further, we also observed a significant decrease in expression of PCNA, COX-2, 5-LOX, and DclK1 in the combination treatment groups (Fig. 6A-6D, Supplementary Fig. 1). In agreement with the apoptosis results, we observed a significant increase in p21 expression (Fig. 6E, Supplementary Fig. 1) and a decrease in $\beta$-catenin in the treatment groups (Fig. 6F, Supplementary Fig. 1). IHC/IHF analysis revealed decreased COX-2, 5-LOX, and pEGFR expression in licofelone+gefitinib treated groups compared with untreated groups (Fig. 7).

\section{Licofelone + gefitinib combination inhibits DclK1-positive stem-like cells}

We have previously shown that DclK1 is a potential stem cell marker for pancreatic carcinogenesis [5]. By inhibiting COX-2, 5-LOX, cytokines, and their receptors, anti-inflammatory agents can block signals from tumor cells, and potentially affect cancer stem cells (CSCs) [2]. We have seen a significant decrease in DclK1 expression in treatment groups (Fig. 8). Combination treatment significantly reduced DclK1 expression (Fig. 8, Supplementary Fig. 1).

\section{Gene expression profiling in pancreatic tumor tissues}

We observed a significant increase in the inflammatory genes COX-2 and 5-LOX, along with EGFR, in the pancreatic tumors from 44-weekold mice compared with pancreata from wild-type mice, as determined by Next Generation Sequencing/ RNAseq analysis (Fig. 9A). However, in the individual and combination drug treatments, these levels were significantly reduced (Fig. 6, 7, Supplementary Fig. 1). To investigate transcriptomic changes in actively progressing pancreatic cancer, we performed Next Generation Sequencing/RNAseq using the pancreatic tissues from mice fed control diet or combination drug treatment for 25 weeks. At the endpoint, PanIN lesions and carcinomas were recorded. The sample numbers met the requirements for statistical significance per $t$-test and Benjamini's 

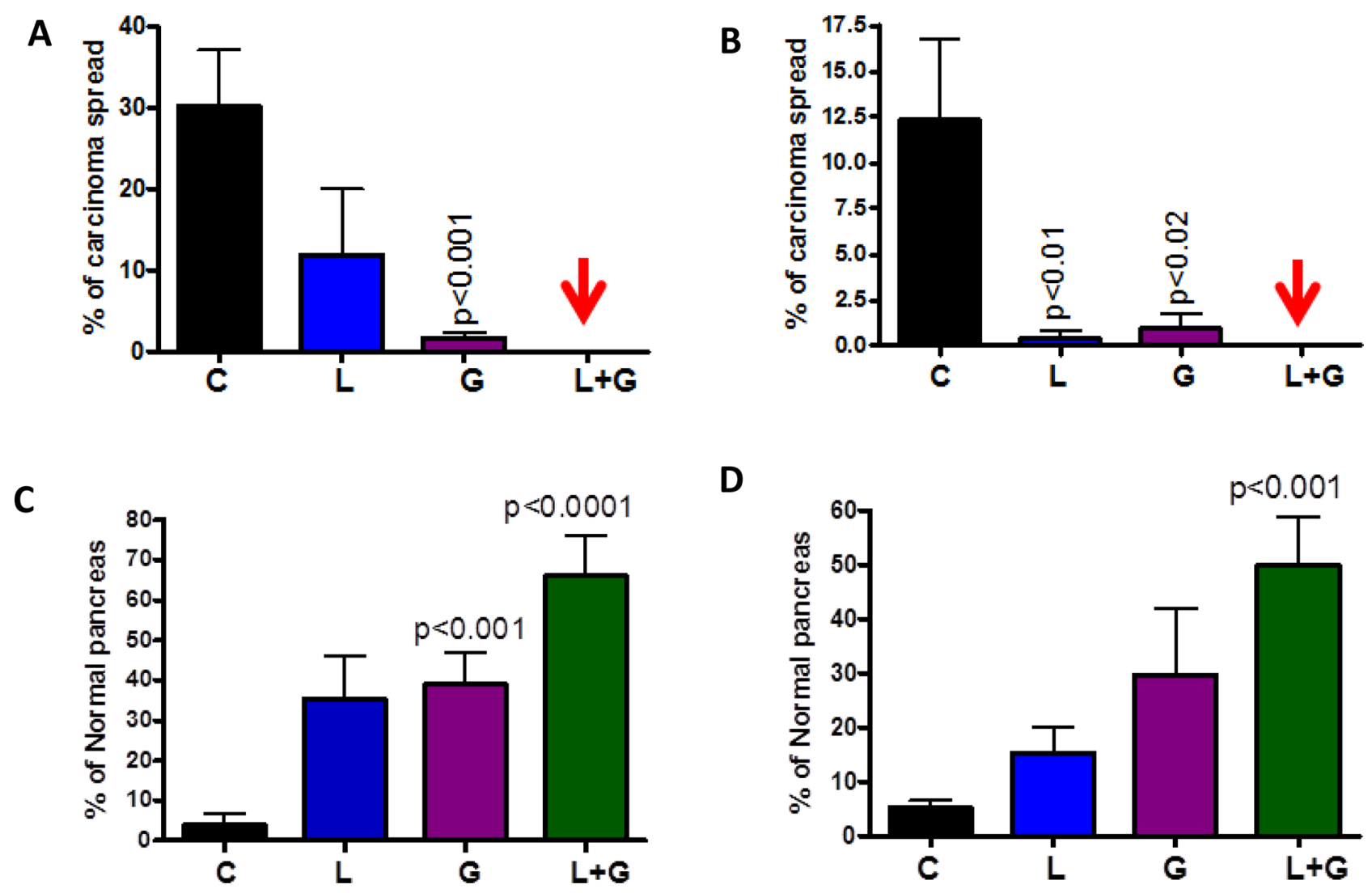

Figure 4: Effect of $\mathbf{L}, \mathbf{G}$ and $\mathbf{L}+\mathbf{G}$ on carcinoma percentage. A-B. Effect of $\mathrm{L}, \mathrm{G}$, and $\mathrm{L}+\mathrm{G}$ on the percentage of pancreata with carcinoma (A-male, B-female). C-D. Effect of L, G, and L+G on the percentage of normal appearing pancreata (C-male, D-female). The data in the panels were analyzed by unpaired $t$-test with Welch's correction. Values are considered statistically significant at $p<0.05$.

and Hochberg tests (3-6 per group). Overall, the gene expression profiles showed a pattern of differences between the control and combination treatment groups in the heat map determined by Strand analysis (Fig. 9B). Further, using the GeneSifter Next generation sequencing data set, we identified differentially expressed genes. There were total 7043 hits with a 1.5-fold expression difference threshold, $p<0.05$ (both upregulated and downregulated genes). The gene data sets 5-LOX activating protein (FLAP), 5-LOX, mPGES-1, mPGES-2, EGFR, and DclK1 were significantly decreased by the combination treatment during the progression of pancreatic lesions to ductal adenocarcinoma (Fig. 9C). Importantly, the combination treatment significantly reduced PanIN1, 2 and 3 lesions (Fig. 9D). These results indicate that both inflammation and EGFR signaling can be tightly regulated by these drugs during PDAC development.

\section{Impact of combination treatment on tumor immune responses and desmoplastic reaction}

Furthermore, the NGS data revealed that dual combination treatment significantly impacted and reduced the matrix metalloproteases (MMP); MMP19, MMP23, MMP9, MMP3, MMP17, MMP12, MMP28 and MMP11 (Table 1). Of all the MMPs, MMP19 was greatly reduced ( $>24$ fold) followed by MMP23 ( $>21$ fold). Notable changes were observed in the genes related to immune responses and desmoplastic reaction (Table 2 ) along with changes in inflammatory genes (Fig. 9C, Table 2). Importantly, the macrophage stimulating receptor (Mst1r) was reduced by $>40$ fold (Table 2). Other genes that were upregulated were galanin recptor 1 (Galr1) (8.96 fold; $p<0.05$ ), tumor suppressor glycine N-methyl transferase Gnmt (4.3 fold; $p<0.02$ ) and fructosamine 3 kinase (Fn3k) (8.24 fold; $p<0.01)$.

\section{DISCUSSION}

Pancreatic cancer treatment is challenging, due to the aggressive nature of the disease and a lack of effective drug treatments. The commonly used FDA-approved drug, gemcitabine, a deoxycytosine analog, represents the current standard-of-care for advanced PC; gemcitabine improves quality of life in a minority of patients [19] and increases survival by few weeks. Studies showed that median survival is extended by 14 days with the use of EGFR inhibitor erlotinib [20]. Understanding pancreatic cancer development and finding ways to treat this disease at all stages are clear and imperative needs [21]. 


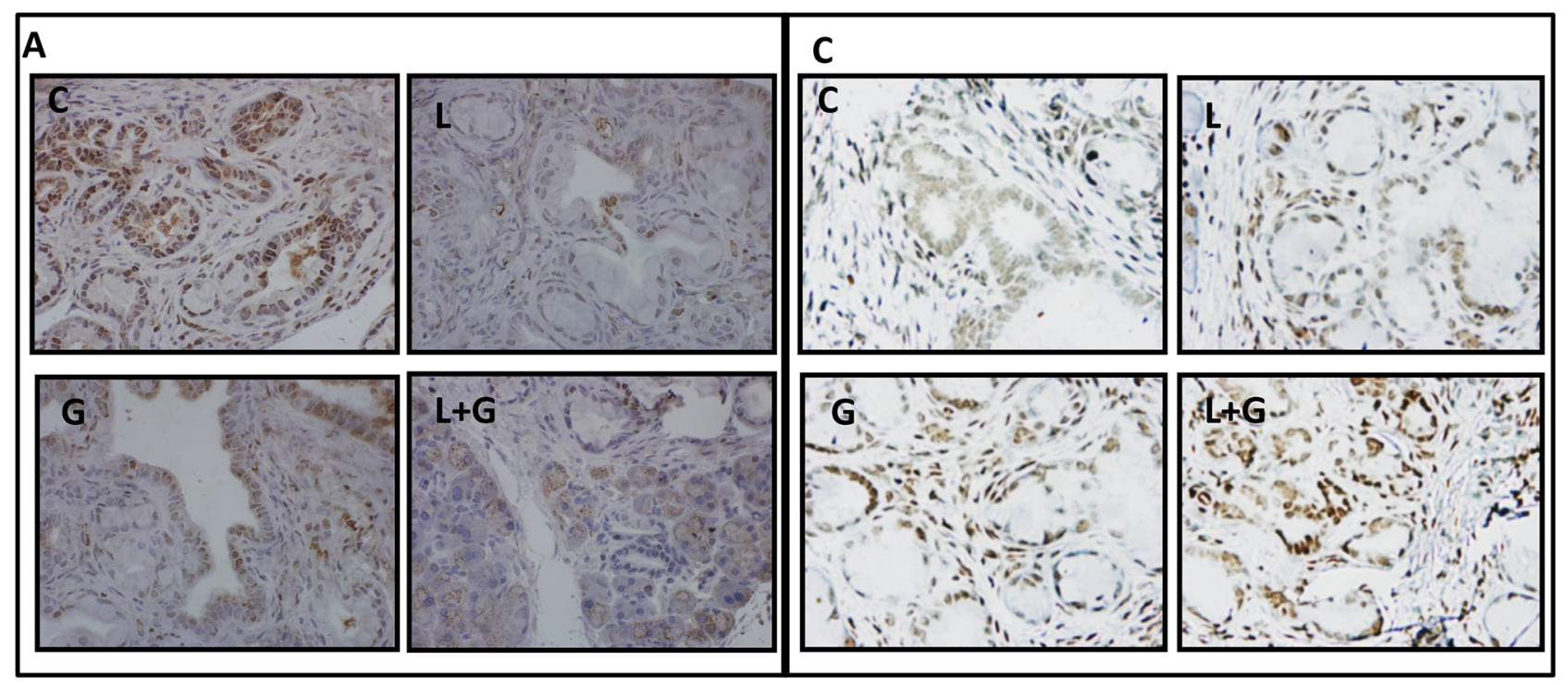

B

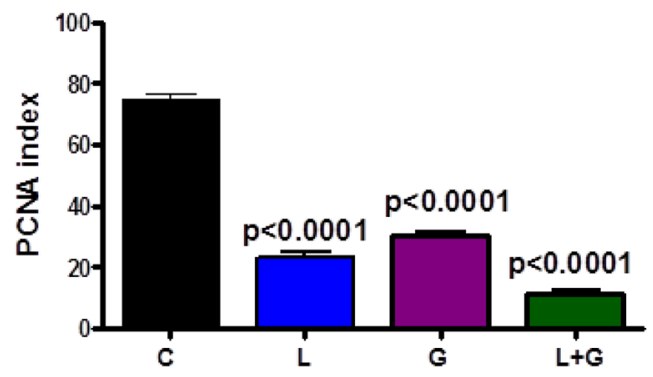

D

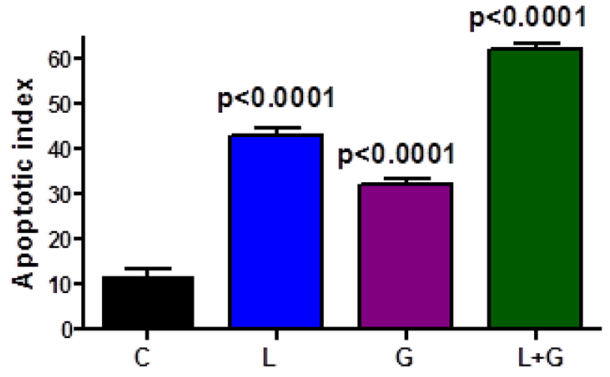

Figure 5: Effect of $\mathbf{L}, \mathbf{G}$, and $\mathbf{L}+\mathbf{G}$ on tumor cell proliferation and apoptosis. A. Immunohistochemical staining for PCNA in pancreatic tumors from GEM fed control diet or treated with L, G, or L+G. B. A significant difference was observed in the proliferative index between combination-treated and control group pancreata. C-D. TUNEL assay was done for apoptotic cells in pancreatic tumors from GEM fed control diet or treated with L, G, or $\mathrm{L}+\mathrm{G}(n=6$ mice/group). A significant induction of apoptosis was observed in tumors from treated mice compared with tumors from untreated mice.

It is well-established that $95 \%$ of the pancreatic cancers are associated with K-ras mutations. Several of the molecular signaling changes occur as the disease progress from initial pancreatic precursor lesions PanINs (PanIN 1 to PanIN 2 to PanIN 3) to ductal adenocarcinoma. Of these, the most commonly observed changes are marked dysregulation of EGFR signaling and inflammatory pathways. EGFR dysregulation is observed in over $87 \%$ of patients with pancreatic cancer [22-24]. Both inflammation and EGFR play a pivotal role in disease progression. During progression of $\mathrm{PC}, \mathrm{COX}-2$, and 5-LOX are over-expressed, along with EGFR (Fig. 9). Studies showed that the activation of the EGFR pathway promotes transcription of the COX-2 gene $[25,26]$. Likewise, the COX-2 signaling pathway activates EGFR phosphorylation [27] and EGFR transcription [28]. The EGFR and COX-2 pathways interact at several levels, and are involved in carcinogenesis, angiogenesis, and chemoresistance. The EGFR pathway plays a central role in the regulation of COX-2 expression. Activation of the Ras/Raf/mitogen-activated protein kinase and NF- $\mathrm{BB}$ transcription factor upregulates $\mathrm{COX}-2$ gene transcription and the activation of the PI3K/Akt pathway stabilizes COX-2 mRNA [25, 26]. Similarly, overexpression of the COX-2 enzyme can potentially affect the EGFR signaling pathway. Prostaglandins (PG) transactivate the EGFR by induction of phosphorylation of the EGFR and extracellular signal-regulated kinase [27]. Further, COX-2 overexpression induces EGFR expression [28]. In addition to COX-2 inhibition, celecoxib is known to directly inhibit the EGFR pathway through inhibition of the PI3K/Akt and NF- $\kappa B$ pathways [29-31]. Although EGFR inhibitors are in use, their benefits are limited and the use of higher doses leads to undesirable side effects and toxicities. Clinically, targeting inflammation by selective COX-2 inhibitors leads to increased cardiovascular and GI toxicities. Therefore, targeting both EGFR and 5-LOX-COX- simultaneously may be an effective approach to modulate three pathways and their downstream signaling, which may result in an increased treatment response. Hence, the aim of this study was to determine whether simultaneous targeting of inflammatory pathways (5-LOX-COX) and EGFR at early stages would lead to blockade of progression of PanIN lesions to carcinoma. 

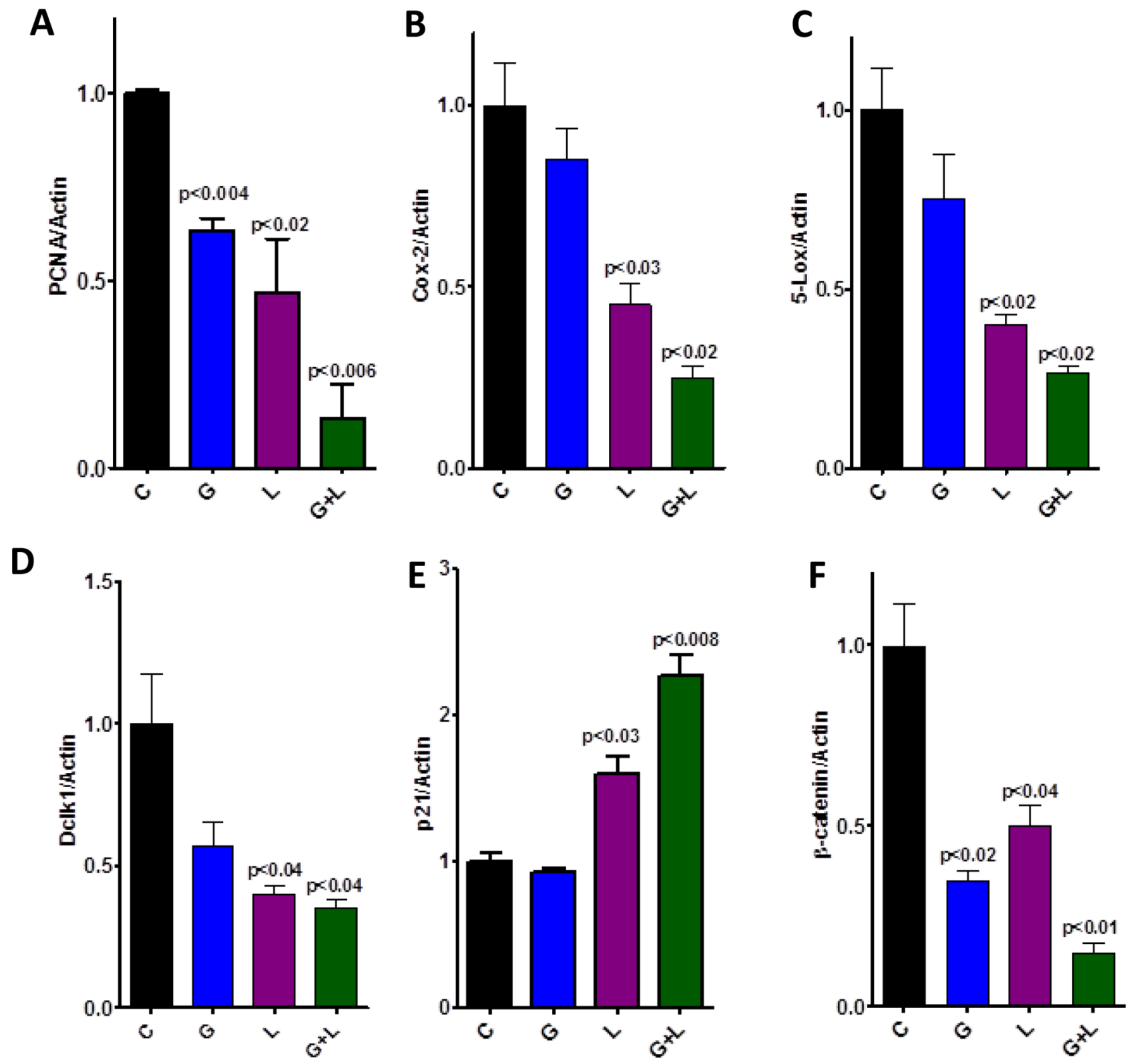

Figure 6: Effect of $\mathrm{L}, \mathrm{G}$, and $\mathrm{L}+\mathrm{G}$ on protein expression of PCNA, COX-2, 5-LOX, DclK1, p21, and $\beta$-catenin, as determined by western immunoblotting. The combination of $\mathrm{L}+\mathrm{G}$ significantly decreased PCNA, COX-2, 5-LOX, DclK1, and $\beta$-catenin expression, with an increase in $\mathrm{p} 21$ expression, compared with individual drug treatment.

We first used transcriptome analysis to establish that COX-2, 5-LOX, and EGFR concurrently overexpress in PDAC from GEM compared with pancreata from wild-type mice (Fig. 9A). We chose licofelone as antiinflammatory agent due to its ability to simultaneously inhibit COX and 5-LOX, which limits undesirable cardiovascular and gastrointestinal side effects, and chose gefitinib as the EGFR inhibitor to study their individual and combined effects on PDAC development. Lower doses of these two agents were selected, based on our previous studies $[5,12]$. In our long-term in vivo efficacy study, we demonstrated that licofelone and gefitinib can target COX-2, 5-LOX, EGFR, and cancer stem cell marker DclK1, and can potently inhibit PanIN progression to PDAC without any side effects.

Male and female mice receiving treatment with licofelone or gefitinib alone showed dramatic inhibition of PDAC incidence. A complete blockade of PDAC (100\% inhibition) was observed with the combination treatment. Up to $70 \%$ of development of carcinoma in situ (PanIN 3 lesions) was blocked by the combination, compared with a $56 \%$ and $50 \%$ blockade by the individual drugs. These results clearly demonstrate that combination treatment effectively blocks progression of PanIN lesions to ductal 


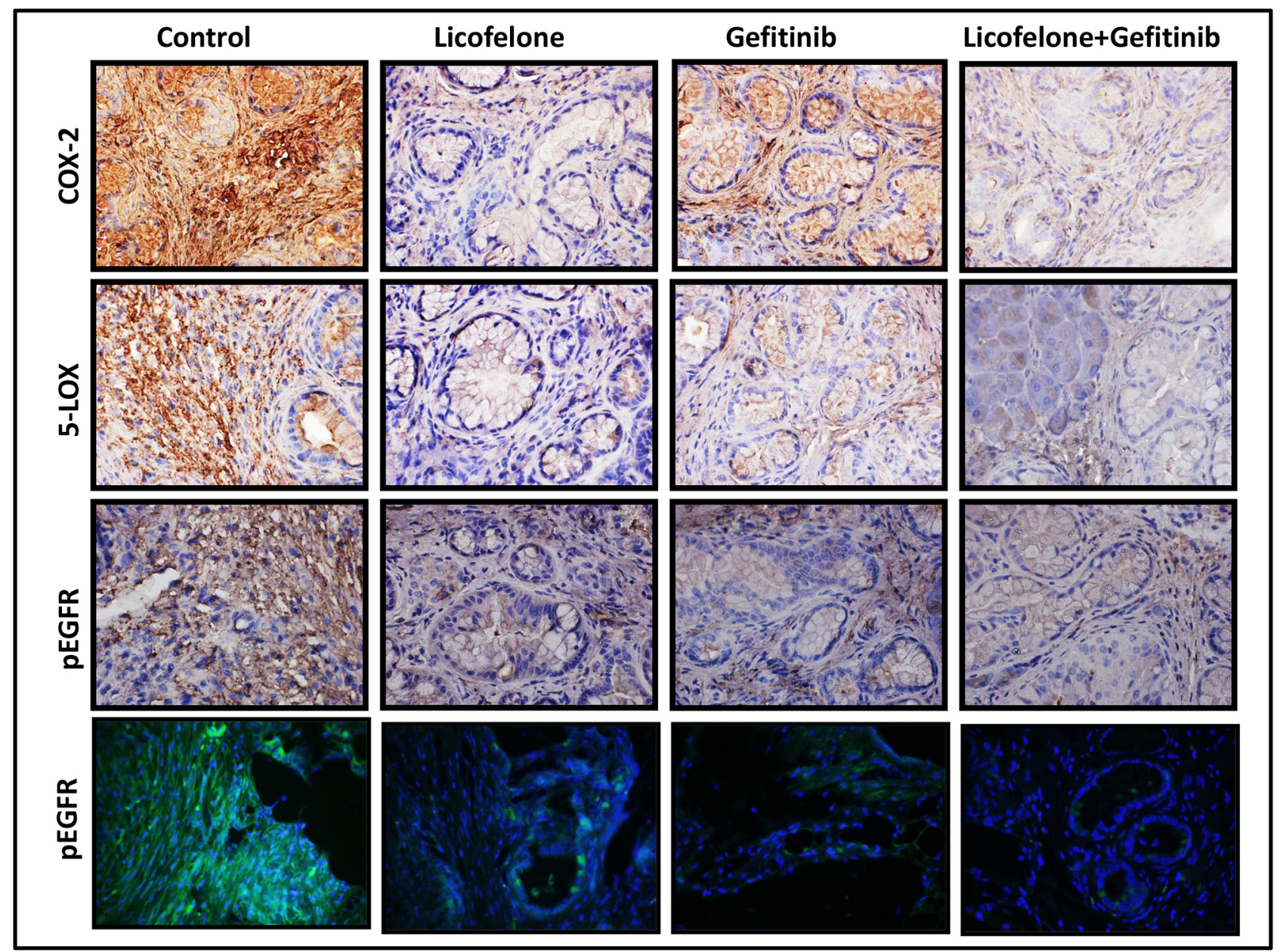

Figure 7: Effect of L, G, and L+G on COX-2, 5-LOX, and p-EGFR. Immunohistochemistry (COX-2, 5-LOX, p-EGFR) and immunofluorescence (bottom row) revealed reduced COX-2, 5-LOX, and p-EGFR expression with individual drug treatment and the combination.

adenocarcinoma. Further, about $70 \%$ of the pancreata from mice receiving the combination treatment were free from PanIN lesions.

We have previously shown in vivo chemopreventive effects of licofelone on colon and bladder cancers [32, 33]. There are limited reports on the evaluation of COX-2 inhibitors, and no reports on dual COX/5-LOX inhibitors used in combination with EGFR inhibitors against PC using a GEM model. For example, the use of selective COX-2 inhibitor nimesulide and NO-aspirin delayed the progression of PC precursor lesions in the Kras ${ }^{\mathrm{G} 12 \mathrm{D}}$ mouse model $[2,3]$. In in vitro studies, the combination of celecoxib, SC-236, and NS-398 with gefitinib, trastuzumab, and cetuximab showed growth inhibition and potentiated the apoptotic effect in squamous cell cancer and breast and colon cancer cell lines [34-36].

The effects of the combination treatment on pancreatic tumor weights were strongly correlated with effects on PDAC incidence, carcinoma in situ development, and incidence of ductal adenocarcinoma. The pancreas weights from GEM receiving the combination treatment were comparable to those of wild-type mice. Previous investigations of our group and others revealed the anti-proliferative and apoptotic effects of licofelone and gefitinib on colon, bladder, and pancreatic cancers [5, 12, 32, 33]. Our results here clearly indicate that the licofelone+gefitinib combination effectively suppressed the growth and progression of PC in GEM. We propose that the synergism obtained due to simultaneous inhibition of 5-LOX-COX- and EGFR at early stages might be an underlying mechanism for the enhanced antitumor effects. In vitro studies of pancreatic cancer reported that a combination of erlotinib and celecoxib downregulated EGFR and COX-2 expression and activation [37]. However, further studies are warranted to establish cause and effect.

In the present study, licofelone+gefitinib suppressed DclK1 CSC marker and inhibited tumor progression, compared with individual drug treatments, suggesting that the combination may effectively act on eliminating CSCs. Though PGE2 is implicated in CSC survival and proliferation, recent evidence shows that 5-LOX is also 


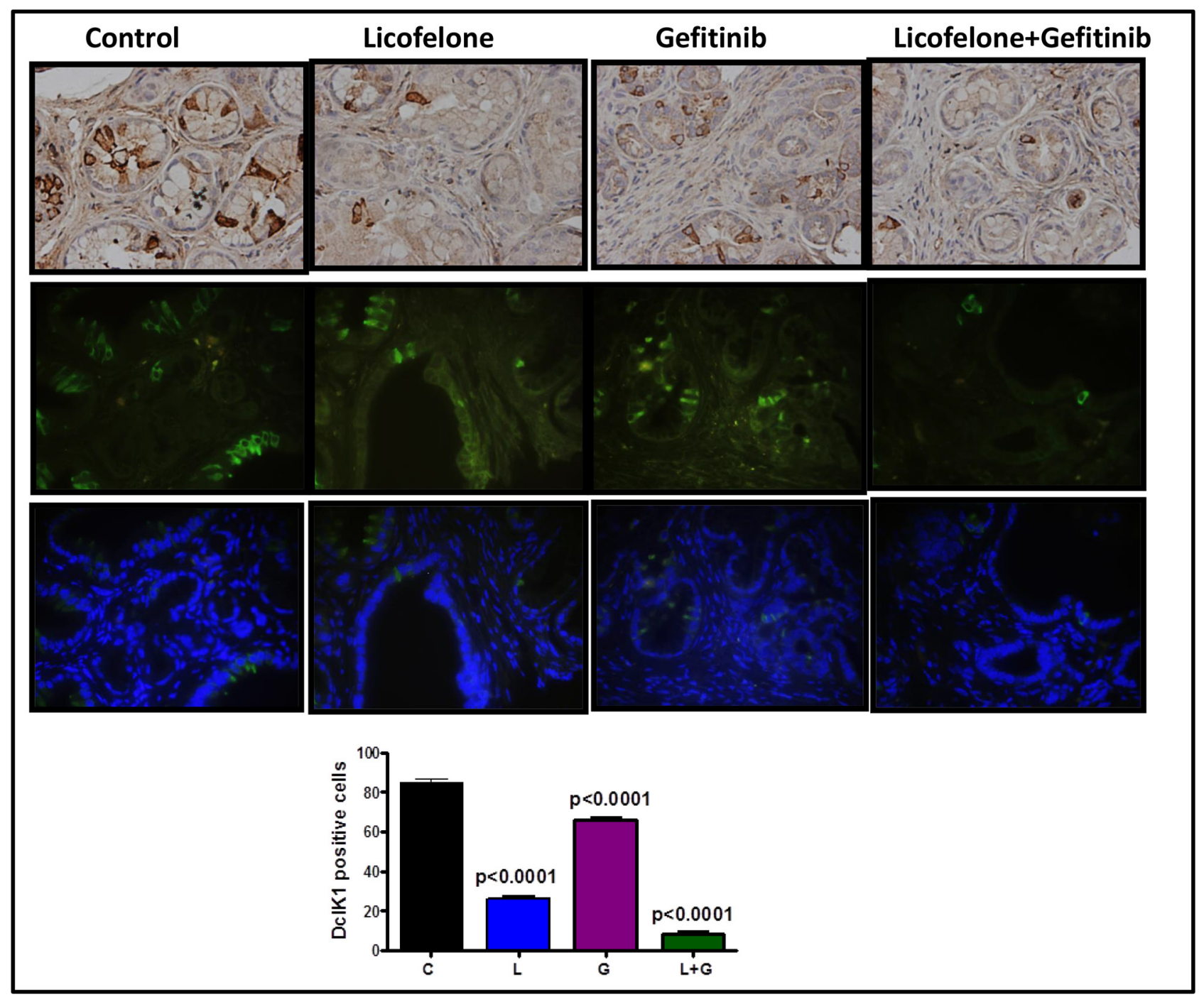

Figure 8: Effect of $\mathbf{L}, \mathbf{G}$, and $\mathbf{L}+\mathbf{G}$ on CSC marker DclK1. Immunohistochemistry (brown-DclK1; top panel) and immunofluorescence (bottom panels; green-DclK1, blue-DAPI) staining for DclK1 in pancreatic tumors from GEM fed control diet or treated with $\mathrm{L}, \mathrm{G}$, or $\mathrm{L}+\mathrm{G}$. A significant decrease in the number of DclK1-positive cells was observed with the combination treatment compared with individual drug treatment and controls.

a candidate for the management of stem cells [38]. We also observed that genetic ablation of COX-2 did not significantly reduce DclK1 in Kras GEM mice [5]. This may be partly attributed to the shift of arachidonic acid metabolism pathways towards 5-LOX upon selective inhibition of COX-2 [5]. Hence, the use of a dual 5-LOX-COX-inhibitor like licofelone is ideal to kill CSCs effectively. Drugs like metformin and licofelone have been shown to specifically target cancer stem cells, thereby showing greater effects in blocking pancreatic and breast tumor growth and prolonging remission $[5,17,39,40]$. The concurrent inhibition of cyclooxygenase- 2 and EGFR leads to greater anti-tumor activity in pancreatic cancer [37]. In addition to COX-2 inhibition, celecoxib is known to directly inhibit the EGFR pathway through inhibition of the PI3K/Akt and NF- $\mathrm{BB}$ pathways [37]. In vitro studies showed no potentiation in growth inhibition or apoptosis in the cell lines with low EGFR expression. However, significant downregulation of COX-2 and EGFR expression was observed in cells with high EGFR expression treated with the combination of erlotinib and celecoxib, compared with individual drugs [37]. Since high EGFR expression is seen in about $87 \%$ of patients with $\mathrm{PC}$, and also reflected in the present study, the combination of licofelone and gefitinib reduced COX-2, 5-LOX, EGFR, DclK1, mPGES-1, mPGES-2, FLAP, and $\beta$-catenin, and increased p21 expression, compared with untreated controls and animals treated with either drug alone. Importantly, number of genes responsible tumor immune responses and desmoplastic reaction; Mst1r, TGF $\beta r 1$, TGF $\beta \mathrm{r} 2$, VEGFa, CSF-1, SDF-2, CD44, IL-6ra, PD1, CD68, CD163, fibronection and MMPs (Tables 1 \& 2) were significantly reduced. Whereas the mRNAs of genes that helps in tumor 
EGFR

A

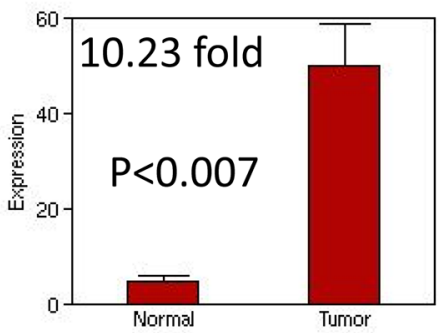

COX-2

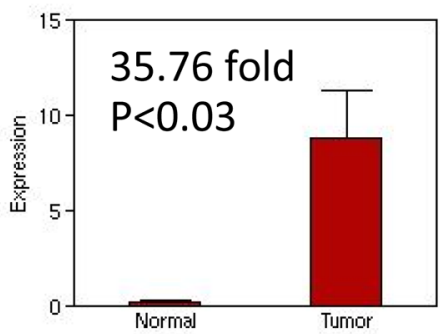

5-LOX

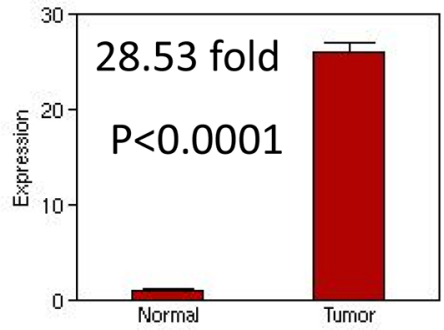

B
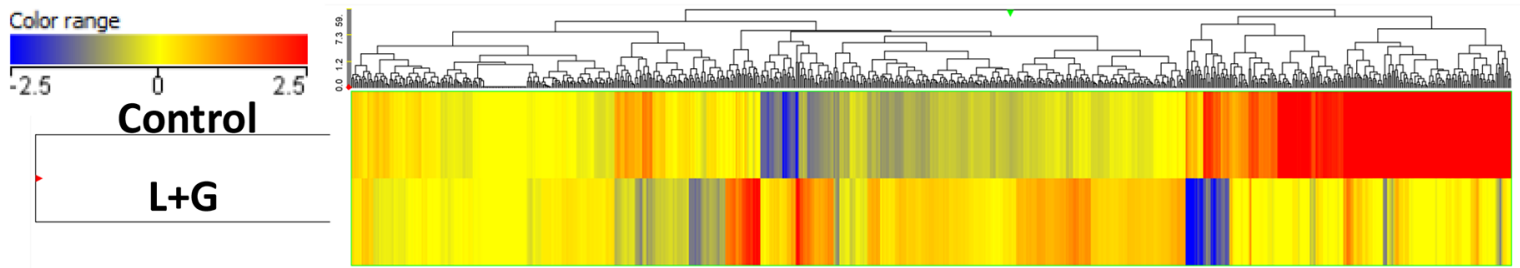

C

\begin{tabular}{|lcl|}
\hline Gene & fold change & ' $\mathrm{p}$ ' value \\
\hline mPGES-1 & 14.97 & $\mathrm{p}<0.03$ \\
mPGES-2 & 3.65 & $\mathrm{p}<0.04$ \\
FLAP & 23.09 & $\mathrm{p}<0.01$ \\
5-LOX & 22.93 & $\mathrm{p}<0.002$ \\
EGFR & 3.87 & $\mathrm{p}<0.003$ \\
DcIK1 & 21.65 & $\mathrm{p}<0.004$ \\
\hline
\end{tabular}

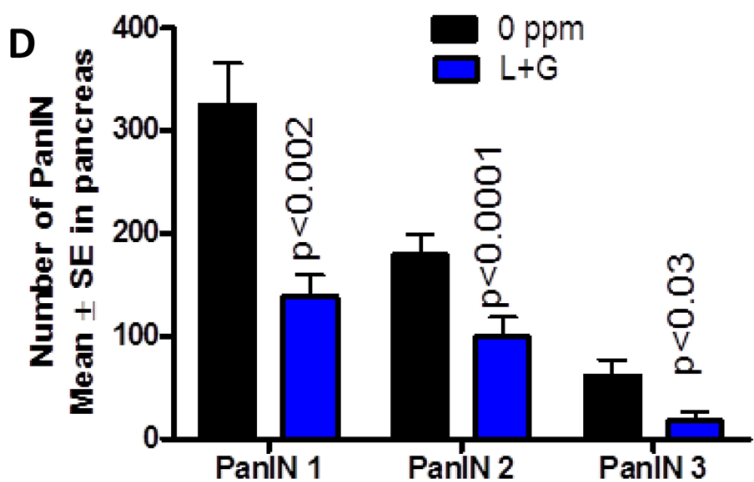

Figure 9: Impact of combination treatment on transcriptomic gene changes. A. Whole genome transcriptome analysis by Illumina sequencing showing increased mRNA expression of EGFR, COX-2, and 5-LOX in pancreata from GEM mice compared with wild-type mice. B. Heat map of the untreated and combination treatment groups showing differential gene expressions. C. Transcriptome gene changes in the down regulated mRNA expression of mPGES-1, mPGES-2, FLAP, 5-LOX, EGFR, and DclK1 upon combination treatment. D. Combination treatment significantly decreased number of PanIN lesions.

Table 1: Transcriptome gene changes in the downregulated mRNA expression of MMPs in response to combination treatment

Gene
\begin{tabular}{|l|c|c|}
\hline MMP 19 & 24.32 & ' $p$ ' value \\
\hline MMP 23 & 21.48 & $<0.002$ \\
\hline MMP 9 & 18.47 & $<0.02$ \\
\hline MMP 3 & 12.04 & $<0.008$ \\
\hline MMP 17 & 11.47 & $<0.02$ \\
\hline MMP 12 & 10.39 & $<0.04$ \\
\hline MMP28 & 10.10 & $<0.002$ \\
\hline MMP 11 & 7.27 & $<0.002$ \\
\hline
\end{tabular}

inhibition like Galr1, tumor suppressor Gnmt and Fn3k were significantly increased. Further, transcriptome data and PanIN lesion inhibition data obtained during the tumor progression stage corroborated with these results (Fig. 9B-9D). Although RNA seq data showed extensive changes with combination treatment, the gene expression 
Table 2: Transcriptome changes in the downregulated mRNA expression of genes related to tumor immune responses and desmoplastic reaction upon combination treatment

\begin{tabular}{|c|c|c|}
\hline Gene & fold change & ' $p$ ' value \\
\hline IL-1 $\beta$ & 13.26 & $<0.002$ \\
\hline Mst1r & 40.06 & $<0.02$ \\
\hline TGFßr1 & 6.09 & $<0.02$ \\
\hline TGF $\beta \mathrm{r} 2$ & 14.09 & $<0.03$ \\
\hline Fibronectin 1 & 18.85 & $<0.03$ \\
\hline PDGF $\beta$ & 3.53 & $<0.02$ \\
\hline PDGFrb & 6.26 & $<0.05$ \\
\hline VEGFa & 1.61 & $<0.03$ \\
\hline CSF-1 & 5.27 & $<0.002$ \\
\hline SDF-2 & 3.24 & $<0.01$ \\
\hline CD44 & 19.82 & $<0.05$ \\
\hline IL-6ra & 4.03 & $<0.02$ \\
\hline PD1 (PDCD1) & 6.80 & $<0.02$ \\
\hline CD68 & 9.99 & $<0.047$ \\
\hline CD163 & 7.26 & $<0.045$ \\
\hline
\end{tabular}

pattern in the tissues did not return to normal after treatment. The reason for this could be due to presence of PanIN lesions even after combination treatment (Fig. 9D).

Mechanistically, the effects of the gefitinib and licofelone combination can be attributed to the inhibition of expression of COX-2, 5-LOX, EGFR, and DclK1, as shown by the schematic diagram in Fig. 10. In addition, the combination significantly downregulated mPGES-1, mPGES-2, and FLAP, which in turn contribute to the release of prostaglandins (PG), leukotrienes, and thromboxane; and changes in the tumor immune responses and desmoplastic reaction. Further studies are warranted to evaluate the exact and in-depth mechanism of this combination treatment. In conclusion, licofelone can potentiate the pancreatic tumor growth inhibitory effects of gefitinib in GEM with pancreatic cancer. Our study reports for the first time the use of combination of a dual 5-LOX-COX-inhibitor, licofelone, with gefitinib in a genetically engineered Kras mouse model that recapitulates human disease progression in a step-wise manner. However, further studies using different GEMs must be conducted to translate this combination approach to the clinic. Therefore, targeting the EGFR and 5-LOXCOX-pathways seems to be a promising approach for the prevention and/or treatment of pancreatic cancer.

\section{MATERIALS AND METHODS}

\section{Mouse model, diet, and handling}

All animal research was performed under the auspices of animal protocols approved by the University of Oklahoma Health Sciences Center institutional animal care and use committee. Animals were housed in ventilated cages under standardized conditions $\left(21^{\circ} \mathrm{C}, 60 \%\right.$ humidity, 12-h light/12-dark cycle, 20 air changes/hour) in the University rodent barrier facility. Semi-purified modified AIN-76A diet ingredients were purchased from Bioserv, Inc., NJ. Generation of $\mathrm{p} 48^{\mathrm{Cre} /+}$-LSL-Kras ${ }^{\mathrm{Gl} \mathrm{D} /+}$ mice expressing the activated $\mathrm{Kras}^{\mathrm{G}}{ }^{\mathrm{I} 2 \mathrm{D}}$ oncogene has been described previously $[17,18]$. The dual $\mathrm{COX} / 5$ LOX inhibitor licofelone and EGFR inhibitor gefitinib were procured from the NCI-DCP chemoprevention drug repository. Mice were allowed ad libitum access to the respective diets (licofelone $250 \mathrm{ppm}$, gefitinib $100 \mathrm{ppm}$, or a combination) and to automated tap water purified by reverse osmosis.

\section{Breeding and genotyping analysis}

LSL-Kras ${ }^{\mathrm{G} 12 \mathrm{D} /+}$ and $\mathrm{p} 48^{\mathrm{Cr} / /}$ mice were maintained in a C57BL/6 heterozygous genetic background. LSL$\mathrm{Kras}^{\mathrm{G} 12 \mathrm{D} /+}$ and $\mathrm{p} 48^{\mathrm{cre} /+}$ mice were bred and offspring of activated $\mathrm{p} 8^{\mathrm{Cre} /} \cdot$. LSL-Kras ${ }^{\mathrm{G} 12 \mathrm{D} / \mathrm{+}}$ and $\mathrm{C} 5 \mathrm{BL} / 6$ wild-type mice were generated at the required quantities. Briefly, genomic DNA was isolated from tail tissue samples using the mini-prep kit (Invitrogen, Carlsbad, CA). Polymerase chain reaction (PCR) was performed for $\mathrm{K}$-ras and Cre genes using the following conditions: denaturation at $95^{\circ} \mathrm{C}$ for $5 \mathrm{~min}$, followed by 35 cycles at $95^{\circ} \mathrm{C}$ for $1 \mathrm{~min}, 60^{\circ} \mathrm{C}$ for $1 \mathrm{~min}$, and $72^{\circ} \mathrm{C}$ for $1 \mathrm{~min}$. Oligonucleotide primer sequences used were as follows: K-ras 5'-CCTTTACAAGCGCACGCAGAG-3' sense, 


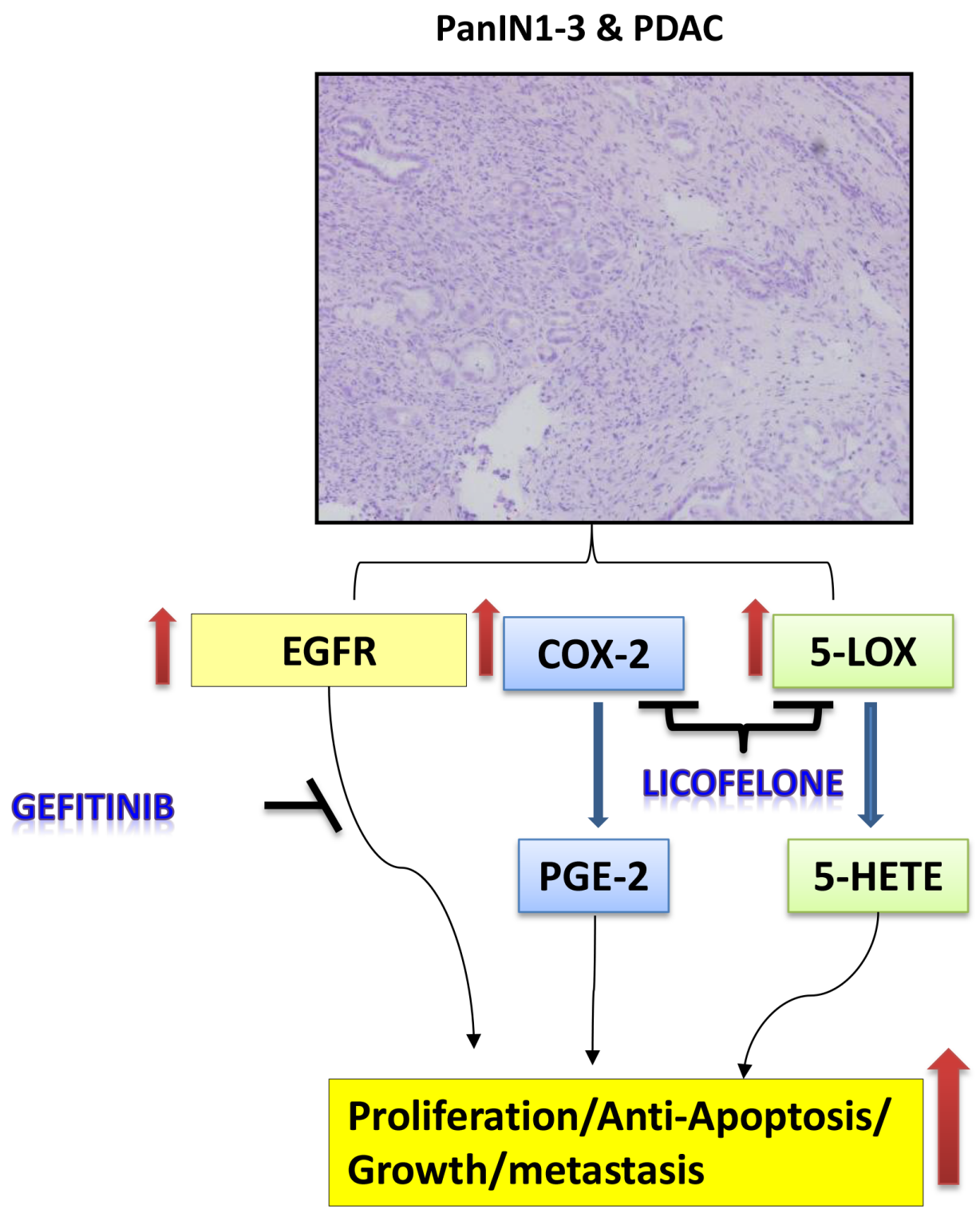

Figure 10: Schematic representation of effects of gefitinib and licofelone on PC progression. Hematoxylin and Eosin staining showing PanINs and PDAC. Pathways showing the effects of gefitinib and licofelone on inhibition of cell proliferation and tumor progression.

\section{5'-AGCTAGCCACCATGGCTTGAGTAAGTCTGCA-3' anti-sense; and p48Cre 5'-ACCGTCAGTACGTGAGAT ATCTT-3' sense and 5-ACCTGAAGATGTTCGCGATTA TCT- 3 ' antisense. PCR products were separated on a $2 \%$ agarose gel. Successful recombination yields were 550 and 350-bp products for Kras and Cre genes respectively (17). The genotype of each pup was confirmed by tail DNA extraction and PCR.}

\section{Preclinical assay: efficacy of licofelone}

Genotyped male and female p48 $8^{\mathrm{Cr} /+}-\mathrm{LSL}-\mathrm{Kras}^{\mathrm{Gl} 2 \mathrm{D} /+}$ transgenic mice were used in the efficacy study. Fiveweek-old mice were selected and randomized so that average body weights in each group were equal. Mice were fed AIN-76A diet for one week. At 6 weeks of age, p48 ${ }^{\mathrm{Cr} /+}$-LSL-Kras ${ }^{\mathrm{G} 12 \mathrm{D} /+}$ mice were fed AIN-76A experimental diets containing $0 \mathrm{ppm}$ drug $(n=34$ /group $+n=12$ C57BL/6 wild-type mice), $250 \mathrm{ppm}(n=28 /$ group) licofelone, $100 \mathrm{ppm}$ ( $n=23 /$ group $)$ gefitinib, or a combination of licofelone+gefitinib $(250 \mathrm{ppm}+100 \mathrm{ppm}$, $n=24$ /group) until termination of the study. After 38 weeks ( $\sim 10$ months) on experimental diets, all mice were euthanized by $\mathrm{CO}_{2}$ asphyxiation and necropsied. Pancreata were collected from all groups, weighed, and snap-frozen in liquid nitrogen for further analysis. Pancreata (head to tail) required for histopathologic and IHC evaluations to identify PanIN lesions and PDAC for evaluation of various molecular markers were fixed in $10 \%$ neutral-buffered formalin, as previously described. 


\section{Tissue processing and histological analysis of PanIN lesions and PDAC}

After euthanizing the mice, pancreata and other key organs, including liver, spleen, kidney, and lung, were collected and weighed. Tissues were fixed in $10 \%$ formalin for $24 \mathrm{~h}$ and routinely processed and embedded in paraffin. Formalin-fixed 4- $\mu \mathrm{m}$ tissue sections of each pancreas were stained with Hematoxylin \& Eosin (H\&E) and were histologically evaluated by a pathologist blinded to the experimental groups. PanIN lesions and carcinoma were classified according to histopathologic criteria as recommended elsewhere [4, 12-18]. To quantify the progression of PanIN lesions, the total number of ductal lesions and their grades were determined [12-18]. Similarly, pancreatic carcinoma and normal appearing pancreatic tissue were evaluated in all animals.

\section{Immunohistochemistry (IHC) and immunofluorescence (IHF)}

Fixed $5-\mu \mathrm{m}$ sections were incubated with primary antibodies in a hybridization chamber for $1 \mathrm{~h}$ at room temperature or overnight at $4{ }^{\circ} \mathrm{C}$. The primary antibodies were proliferating cell nuclear antigen (PCNA), COX-2, 5-LOX, and pEGFR procured from Santa Cruz/Abcam/ Cell Signaling. Following incubation with primary antibody, sections were incubated for $1 \mathrm{~h}$ with antimouse/anti-rabbit/anti-goat secondary antibody, then were visualized with diaminobenzidine (DAB) and were counterstained with hematoxylin for IHC or with DAPI for IHF. Slides were observed under an Olympus microscope 1X701. Digital computer images were recorded with an Olympus DP70 camera.

\section{Apoptosis assay}

Paraffin sections ( $n=6$ mice/group) of $5-\mu \mathrm{m}$ thickness that had been mounted on slides were rehydrated and stained using the Fragment End Labeling (FragEL) DNA Fragmentation Detection Kit with the TUNEL method, following the manufacturer's instructions (Millipore, Billerica, MA). This kit allows the recognition of apoptotic nuclei in paraffin-embedded tissue sections fixed on slides by FragEL of DNA. The terminal deoxynucleotidyl transferase binds to exposed ends of DNA fragments generated in response to apoptotic signals, and catalyzes the template-dependent addition of biotin-labeled and biotin-unlabeled deoxynucleotides. Biotinylated nucleotides are detected using streptavidinHRP conjugate. Diaminobenzidine reacts with the labeled sample to generate an insoluble colored product at the site of DNA fragmentation. Counter-staining with methyl green aids in the morphologic evaluation and characterization of normal and apoptotic cells. Stained apoptotic epithelial cells (a minimum of 10 microscopic fields per section) were counted manually in a single-blind fashion.

\section{Western blot analysis}

Proteins (60 ug) in lysates from pancreata from control and drug-treated mice were separated by SDSPAGE and were transferred to a nitrocellulose membrane. Membranes were blocked with 5\% nonfat milk (Biorad) in Tris-buffered saline (TBS), and were then incubated with antibodies for PCNA, COX-2, 5-LOX, Dclk1, p21, $\beta$-catenin, and actin overnight at $4^{\circ} \mathrm{C}$. Subsequently, membranes were washed and incubated with HRPsecondary antibody for $1 \mathrm{~h}$. Protein was detected on BioMax MR film (Kodak) using chemiluminescence (Super Signal, Pierce Biotechnology). Equal protein loading was confirmed by detection of actin. ImageJ was used to perform image analysis.

\section{Next generation sequencing (NGS)/RNA-seq and data analyses}

Pancreatic tumor tissues were collected from at least three untreated control mice and three combination-drugtreated mice, after 25 weeks of drug treatment. Total RNA was extracted with Trizol reagent (Life Technologies, San Francisco, CA) and subjected to cDNA library construction, followed by NGS, per the NGS protocol, with an Illumina sequencer in the OUHSC core facility (Microgen). The sequence data was deposited to the Geospiza/Perkin Elmer (Seattle, WA) company server and analyzed with GeneSifter bioinformatics software. The same data set was also analyzed with Strand bioinformatics software (Strand-NGS, San Francisco, CA).

\section{Statistical analysis}

The data are presented as means $\pm S E$. Differences in body weights were analyzed by ANOVA. Statistical differences between control and treated groups were evaluated using Fisher's exact test for PDAC incidence. Unpaired $t$-test with Welch's correction was used for PanIN and PDAC lesions. Differences between groups are considered significant at $p<0.05$.

\section{ACKNOWLEDGMENTS AND GRANT SUPPORT}

The authors thank the University of Oklahoma Health Sciences Center Rodent Barrier Facility staff. We also want to thank Kathy Kyler for valuable suggestions and editorial help. We also thank the Laboratory for Genomics and Bioinformatics at the OUHSC for providing core services for sequencing of pancreatic tissues. Transcriptome analysis was supported by the National 
Center for Research Resources and the National Institute of General Medical Sciences of the National Institutes of Health through Grant Number 8P20GM103447.

This work was supported in part by the National Cancer Institute grant N01-CN-53300 and Kerley-Cade Endowed Chair Fund to C.V. Rao.

\section{CONFLICTS OF INTEREST}

The authors declare no conflict of interest.

\section{REFERENCES}

1. American Cancer Society 2015. Cancer facts and figures. 2015; Atlanta, GA.

2. Rao CV, Mohammed A, Janakiram NB, Qian L, Ritchie RL, Lightfoot S, Vibhudutta A, Steele VE. Inhibition of Pancreatic Intraepithelial Neoplasia Progression to Carcinoma by Nitric Oxide-Releasing Aspirin in p48Cre/+LSL-KrasG12D/+ Mice. Neoplasia. 2012; 14:778-787.

3. Funahashi H, Satake M, Dawson D, Huynh NA, Reber HA, Hines OJ, Eibl G. Delayed progression of pancreatic intraepithelial neoplasia in a conditional $\mathrm{Kras}(\mathrm{G} 12 \mathrm{D})$ mouse model by a selective cyclooxygenase- 2 inhibitor. Cancer Res. 2007; 67:7068-7071.

4. Silvia D. Stan, Shivendra V. Singh, Randall E. Brand. Chemoprevention strategies for pancreatic cancer. Nat Rev Gastroenterol Hepatol. 2010; 7:347-356.

5. Mohammed A, Janakiram NB, Madka V, Brewer M, Ritchie RL, Lightfoot S, Kumar G, Sadeghi M, Patlolla JM, Yamada HY, Cruz-Monserrate Z, May R, Houchen CW, et al. Targeting pancreatitis blocks tumor-initiating stem cells and pancreatic cancer progression. Oncotarget. 2015; 6:15524-15539.

6. Solomon SD, McMurray JJ, Pfeffer MA, Wittes J, Fowler R, Finn P, Anderson WF, Zauber A, Hawk E. Adenoma Prevention with Celecoxib (APC) Study Investigators. Cardiovascular risk associated with celecoxib in a clinical trial for colorectal adenoma prevention. $\mathrm{N}$ Engl J Med. 2005; 352:1071-1080.

7. Arber N, Eagle CJ, Spicak J, Rácz I, Dite P, Hajer J, Zavoral M, Lechuga MJ, Gerletti P, Tang J, Rosenstein RB, Macdonald K, Bhadra P, et al. Celecoxib for the prevention of colorectal adenomatous polyps. N Engl J Med. 2006; 355:885-895.

8. Bertagnolli MM, Eagle CJ, Zauber AG, Redston M, Breazna A, Kim KM, Tang J, Rosenstein RB, Umar A, Bagheri D, Collins NT, Burn J, Chung DC, et al. Five-year efficacy and safety analysis of the Adenoma Prevention with Celecoxib Trial. Cancer Prev Res. 2009; 2:285-287.

9. Duffield-Lillico AJ, Boyle JO, Zhou XK, Ghosh A, Butala GS, Subbaramaiah K, Newman RA, Morrow JD, Milne GL, Dannenberg AJ. Levels of prostaglandin E metabolite and leukotriene E4 are increased in the urine of smokers: evidence that celecoxib shunts arachidonic acid into the 5-lipoxygenase pathway. Cancer Prev Res. 2009; 2:322-329.

10. Bergmann F, Moldenhauer G, Herpel E, Gaida MM, Strobel O, Werner J, Esposito I, Müerköster SS, Schirmacher P, Kern MA. Expression of L1CAM, COX-2, EGFR, c-KIT and Her2/neu in anaplastic pancreatic cancer: putative therapeutic targets? Histopathology. 2010; 56:440-448.

11. Mohammed A, Janakiram NB, Lightfoot S, Gali H, Vibhudutta A, Rao CV. Early Detection and Prevention of Pancreatic Cancer: Use of Genetically Engineered Mouse Models and advanced Imaging Technologies. Cur Med Chem. 2012; 19:3701-3713.

12. Mohammed A, Janakiram NB, Li Q, Madka V, Ely M, Lightfot S, Crawford H, Steele VE, Rao CV. The Epidermal Growth Factor Receptor Inhibitor Gefitinib Prevents the Progression of Pancreatic Lesions to Carcinoma in a Conditional LSL-KrasG12D/+ Transgenic Mouse Model. Cancer Prev Res. 2010; 11:1417-1426.

13. Mohammed A, Qian L, Janakiram NB, Lightfoot S, Steele VE, Rao CV. Atorvastatin delays progression of pancreatic lesions to carcinoma by regulating PI3/AKT signaling in p48Cre/1 LSL-KrasG12D/1 mice. Int J Cancer. 2012; 131:1951-1962.

14. Mohammed A, Janakiram NB, Brewer M, Duff A, Lightfoot S, Brush RS, Anderson RE, Rao CV. Endogenous n-3 Polyunsaturated Fatty Acids delay progression of Pancreatic Ductal Adenocarcinoma in Fat-1.P48Cre/+LSLKrasG12D/+ mice. Neoplasia. 2012; 14:1249-1259.

15. Rao CV, Mohammed A, Janakiram NB, Qian L, Ritchie RL, Lightfoot S, Vibhudutta A, Steele VE. Inhibition of Pancreatic Intraepithelial Neoplasia Progression to Carcinoma by Nitric Oxide-Releasing Aspirin in p48Cre/+LSL-KrasG12D/+ Mice. Neoplasia. 2012; 14:778-787.

16. Hocker JR, Mohammed A, Aston CE, Brewer M, Lightfoot SA, Rao CV, Hanas JS. Mass Profiling of Serum to Distinguish Mice with Pancreatic Cancer Induced by a Transgenic Kras Mutation. Int J Cancer. 2013; 133:2662-2671.

17. Mohammed A, Janakiram NB, Brewer M, Ritchie RL, Marya A, Lightfoot S, Steele VE, Rao CV. Antidiabetic Drug Metformin Prevents Progression of Pancreatic Cancer by Targeting in Part Cancer Stem Cells and mTOR Signaling. Transl Oncol. 2013; 6:649-659.

18. Mohammed A, Janakiram NB, Madka V, Ritchie RL, Brewer M, Biddick L, Patlolla JM, Sadeghi M, Lightfoot S, Steele VE, Rao CV. Eflornithine (DFMO) Prevents Progression of Pancreatic Cancer by Modulating Ornithine Decarboxylase Signaling. Cancer Prev Res. 2014; 7:1198-1209.

19. Burris HA 3rd, Moore MJ, Andersen J, Green MR, Rothenberg ML, Modiano MR, Cripps MC, Portenoy RK, Storniolo AM, Tarassoff P, Nelson R, Dorr FA, Stephens CD, et al. Improvements in survival and clinical 
benefit with gemcitabine as first-line therapy for patients with advanced pancreas cancer: a randomized trial. J Clin Oncol. 1997; 15:2403-2413.

20. Moore MJ, Goldstein D, Hamm J, Figer A, Hecht JR, Gallinger S, Au HJ, Murawa P, Walde D, Wolff RA, Campos D, Lim R, Ding K, et al. Erlotinib plus gemcitabine compared with gemcitabine alone in patients with advanced pancreatic cancer: a phase III trial of the National Cancer Institute of Canada Clinical Trials Group. J Clin Oncol. 2007; 25:1960-1966.

21. Provenzano PP, Cuevas C, Chang AE, Goel VK, Von Hoff DD, Hingorani SR. Enzymatic targeting of the stroma ablates physical barriers to treatment of pancreatic ductal adenocarcinoma. Cancer Cell. 2012; 21:418-429.

22. Pryczynicz A, Guzinska-Ustymowicz K, Kemona A, Ewska JC. Expression of EGF and EGFR Strongly Correlates with Metastasis of Pancreatic Ductal Carcinoma. Anticancer Res. 2004; 28:1399-1404.

23. Durkin AJ, Bloomston PM, Rosemurgy AS, Giarelli N, Cojita D, Yeatman TJ, Zervos EE. Defining the role of the epidermal growth factor receptor in pancreatic cancer grown in vitro. Am J Surg. 2003; 186:431-436.

24. Korc M, Chandrasekar B, Yamanaka Y, Friess H, Buchier M, Beger HG. Overexpression of the epidermal growth factor receptor in human pancreatic cancer is associated with concomitant increases in the levels of epidermal growth factor and transforming growth factor alpha. J Clin Invest. 1992; 90:1352-1360.

25. Elder DJ, Halton DE, Playle LC, Paraskeva C. The MEK/ERK pathway mediates COX-2-selective NSAIDinduced apoptosis and induced COX-2 protein expression in colorectal carcinoma cells. Int J Cancer. 2002; 99:323-327.

26. Sheng H, Shao J, DuBois RN. Akt/PKB activity is required for Ha-Ras-mediated transformation of intestinal epithelial cells. J Biol Chem. 2001; 276:14498-14504.

27. Pai R, Soreghan B, Szabo IL, Pavelka M, Baatar D, Tarnawski AS. Prostaglandin E2 transactivates EGF receptor: a novel mechanism for promoting colon cancer growth and gastrointestinal hypertrophy. Nat Med. 2002; 8:289-293.

28. Kinoshita T, Takahashi Y, Sakashita T, Inoue H, Tanabe T, Yoshimoto T. Growth stimulation and induction of epidermal growth factor receptor by overexpression of cyclooxygenases 1 and 2 in human colon carcinoma cells. Biochim Biophys Acta. 1999; 1438:120-130.

29. El-Rayes BF, Ali S, Sarkar FH, Philip PA. Cyclooxygenase-2-dependent and -independent effects of celecoxib in pancreatic cancer cell lines. Mol Cancer Ther. 2004; 3:1421-6.

30. Arico S, Pattingre S, Bauvy C, Gane P, Barbat A, Codogno P, Ogier-Denis E. Celecoxib induces apoptosis by inhibiting 3-phosphoinositide-dependent protein kinase-1 activity in the human colon cancer HT-29 cell line. J Biol Chem. 2002; 277:27613-27621.
31. Zhu J, Huang JW, Tseng PH, Yang YT, Fowble J, Shiau CW, Shaw YJ, Kulp SK, Chen CS. From the cyclooxygenase-2 inhibitor celecoxib to a novel class of 3-phosphoinositide-dependent protein kinase-1 inhibitors. Cancer Res. 2004; 64:4309-4318.

32. Mohammed A, Janakiram NB, Li Q, Choi CI, Zhang Y, Steele VE, Rao CV. Chemoprevention of colon and small intestinal tumorigenesis in APC(Min/+) mice by licofelone, a novel dual 5-LOX/COX inhibitor: potential implications for human colon cancer prevention. Cancer Prev Res. 2011; 4:2015-2026.

33. Madka V, Mohammed A, Li Q, Zhang Y, Patlolla JM, Biddick L, Lightfoot S, Wu XR, Steele V, Kopelovich L, Rao CV. Chemoprevention of urothelial cell carcinoma growth and invasion by the dual COX-LOX inhibitor licofelone in UPII-SV40T transgenic mice. Cancer Prev Res. $2014 ; 7: 708-716$.

34. Chen Z, Zhang X, Li M, Wang Z, Wieand HS, Grandis JR, Shin DM. Simultaneously targeting epidermal growth factor receptor tyrosine kinase and cyclooxygenase-2, an efficient approach to inhibition of squamous cell carcinoma of the head and neck. Clin Cancer Res. 2004; 10:5930-5939.

35. Tortora G, Caputo R, Damiano V, Melisi D, Bianco R, Fontanini G, Veneziani BM, De Placido S, Bianco AR, Ciardiello F. Combination of a selective cyclooxygenase-2 inhibitor with epidermal growth factor receptor tyrosine kinase inhibitor ZD1839 and protein kinase A antisense causes cooperative antitumor and antiangiogenic effect. Clin Cancer Res. 2003; 9:1566-1572.

36. Half E, Freeburg E, Sun Y, Sinicrope F. EGFR and HER-2 receptor blockade attenuate cyclooxygenase-2 expression and augment NSAID-mediated apoptosis in human colon cancer cells. In: Miami: ASCO GI Cancer Symposium. 2005.

37. Ali S, El-Rayes BF, Sarkar FH, Philip PA. Simultaneous targeting of the epidermal growth factor receptor and cyclooxygenase-2 pathways for pancreatic cancer therapy. Mol Cancer Ther. 2005; 4:1943-1951.

38. Roos J, Oancea C, Heinssmann M, Khan D, Held H, Kahnt AS, Capelo R, la Buscató E, Proschak E, Puccetti E, Steinhilber D, Fleming I, Maier TJ, et al. 5-Lipoxygenase is a candidate target for therapeutic management of stem cell-like cells in acute myeloid leukemia. Cancer Res. 2014; 74:5244-5255.

39. Bao B, Wang Z, Ali S, Ahmad A, Azmi AS, Sarkar SH, Banerjee S, Kong D, Li Y, Thakur S, Sarkar FH. Metformin inhibits cell proliferation, migration and invasion by attenuating CSC function mediated by deregulating miRNAs in pancreatic cancer cells. Cancer Prev Res. 2012; 5:355-364.

40. Hirsch HA, Iliopoulos D, Tsichlis PN, Struhl K. Metformin selectively targets cancer stem cells, and acts together with chemotherapy to block tumor growth and prolong remission. Cancer Res. 2009; 69:7507-7511. 